\title{
Restenosis after elective coronary balloon angioplasty in patients with end stage renal disease: a case-control study using quantitative coronary angiography
}

Frank-Chris Schoebel, Frank Gradaus, Katrin Ivens, Peter Heering, Thomas Walter Jax, Bernd Grabensee, Bodo-Eckehard Strauer, Matthias Leschke

\begin{abstract}
Objective-To assess the rate of angiographic restenosis in patients with end stage renal disease after elective coronary angioplasty.

Design-A retrospective case-control study of 20 patients with end stage renal disease and 20 sex and age matched controls without renal disease, who had undergone primarily successful coronary angioplasty. Control coronary angiography was performed regardless of worsening or renewed incidence of anginal symptoms.

Main outcome measures-Group comparison of coronary morphology, as evaluated by quantitative coronary angiography, and of cardiovascular risk factors.

Results-The rate of angiographic restenosis was $60 \%$ in patients with renal disease and $35 \%$ in controls. In patients with end stage renal disease the following differences (mean (SD) were found versus controls: raised plasma fibrinogen (483 (101) v 326 (62) mg/dl, p < 0.001); raised plasma triglyceride $(269$ (163) $v$ 207 (176) $\mathrm{mg} / \mathrm{dl}$, p < 0.01); smaller diameter of the coronary reference segment (2.59 (0.87) $v 2.90(0.55) \mathrm{mm}, \mathrm{p}<0.10)$; smaller minimum luminal diameter of the dilated stenosis $(0.77(0.46) \quad v \quad 0.97$ $(0.27) \mathrm{mm}, \mathrm{p}<0.05)$. Discriminant analysis showed that minimum luminal diameter before angioplasty $(r=-0.79)$ and fibrinogen $(r=+0.34)$ had the highest statistical association with restenosis.

Conclusions-The high rate of angiographic restenosis in patients with end stage renal disease seems to be related to the size of the vessel dilated and to an increased prothrombotic risk, as indicated by higher fibrinogen concentrations.
\end{abstract}

(Heart 1997;78:337-342)

Keywords: renal disease; coronary artery disease; coronary angioplasty; restenosis

Patients with end stage renal disease have an increased risk of developing coronary artery disease. Their rate of cardiovascular mortality is approximately $50 \%$ - five to 10 times higher than in the general population. ${ }^{1-4}$ Efforts to optimise the medical management of these patients in order to improve their quality of life and survival prospects are thus warranted.

Percutaneous transluminal coronary angioplasty (PTCA) has proved effective in reducing myocardial ischaemia and clinical symptoms in patients with coronary artery disease. In the general population the primary success rate is high, ranging between $90 \%$ and $95 \%$, but late haemodynamically relevant restenosis occurs after a period of about 12 weeks in $30-45 \%$ of the cases. ${ }^{5-7}$ In patients with end stage renal disease an increased risk of procedural complications, an adverse long term clinical outcome, and a high rate of clinical and angiographic restenosis $(60-82 \%$ and $69-100 \%$, respectively) have been reported. ${ }^{8-10}$ These studies were biased towards a high rate of angiographic restenosis, as only patients with recurrent anginal symptoms were included for angiographic follow up.

In an attempt to supply more valid data on the true rate of angiographic restenosis, we compared suitable patients with end stage renal disease who had undergone their first, primarily successful coronary balloon angioplasty with age and sex matched controls for coronary morphology, angiographic variables, and cardiovascular risk factors.

\section{Methods}

PATIENTS

In a retrospective case-control study, 20 patients with end stage renal disease who had undergone first, elective, and primarily successful coronary angioplasty were compared with 20 age and sex matched controls who had been randomly selected from the PTCA registry of our institution. As standard clinical practice, all patients had been followed up angiographically regardless of subjective and objective signs of myocardial ischaemia. The following were not included in the analysis: (1) patients with unstable angina, as defined by a recent onset or change of clinical symptoms (frequency, intensity, and characteristics of anginal pain); (2) patients who presented with complete occlusion of the target vessel or suffered procedural complications like large, flow limiting dissections or early reocclusion of the vessel dilated.

\section{LABORATORY VARIABLES}

Total cholesterol and triglycerides were determined with colorimetric tests (Boehringer Mannheim, Germany)-the CHOD-PAP 
Table 1 Patient characteristics

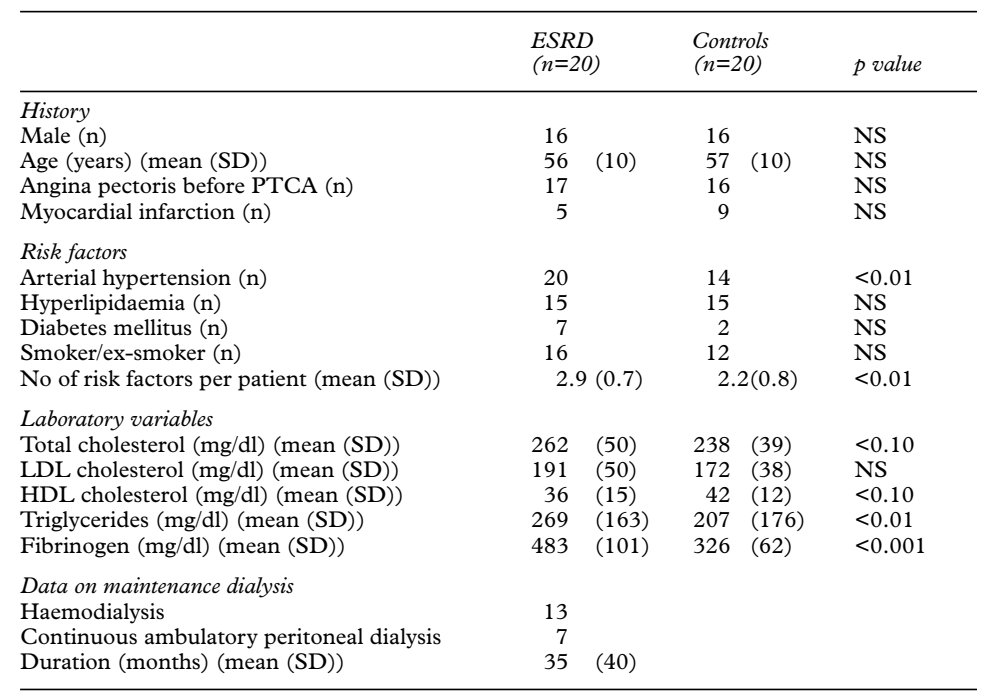

ESRD, end stage renal disease. urements were made without knowledge of the patient's history or clinical data. The image of the first angiogram which showed the most severe coronary narrowing at end diastole was compared with identical projections of the same region obtained immediately after angioplasty and at long term follow up. The computer measured the absolute values of the stenosis and reference locations, using the known catheter diameter as a scaling device.

A single observer trained in quantitative coronary angiography performed the analysis. Intraobserver variability was determined from 20 randomly selected films. Repeated measurements were made after a three month interval without preselection of images. The variability in measurements of coronary angiograms was expressed by the standard deviation of the difference between paired measurements and ranged within the known limits $(0.20 \mathrm{~mm}$ for the minimum luminal diameter, $0.31 \mathrm{~mm}$ for the reference luminal diameter, $4.9 \%$ for per cent diameter stenosis)..$^{13}$

As further dependent variables of coronary angioplasty, acute luminal gain (minimum luminal diameter immediately after angioplasty minus minimum luminal diameter before angioplasty), late luminal loss (minimum luminal diameter immediately after angioplasty minus minimum luminal diameter at follow up), and net luminal gain (minimum luminal diameter at follow up minus minimum luminal diameter before angioplasty) were calculated in absolute changes ( $\mathrm{mm}$ ). Restenosis was defined by the presence of a stenosis $>50 \%$ luminal diameter at the time of follow up.

CORONARY ANGIOGRAPHY AND ANGIOPLASTY

Selective coronary angiography was performed following the administration of intracoronary glyceryl trinitrate, and at least six standardised projections of the left coronary artery and two of the right coronary artery were obtained. The severity of coronary artery disease was determined visually and was classified as single, double, or triple vessel disease, defined by the presence of haemodynamically relevant stenoses (stenosis $>50 \%$ of the luminal diameter) in one of the three major coronary vessels. Complexity of the target lesion was characterised as concentric, eccentric, and multiple irregular stenosed. ${ }^{12}$

Coronary balloon angioplasty was performed with balloon sizes ranging from 2.5$3.5 \mathrm{~mm}$. Before the procedure patients received $500 \mathrm{mg}$ of aspirin and $10000 \mathrm{IU}$ of heparin plus an extra 5000 IU intravenously after the intervention, regardless of the regular daily oral medication, which included aspirin in all patients. Follow up coronary angiography was carried out as a routine procedure after approximately six months, regardless of the presence of clinical symptoms or results from non-invasive measurements of myocardial ischaemia.

QUANTITATIVE CORONARY ANGIOGRAPHY All cineangiograms were evaluated with respect to quantitative coronary morphology by means of computer assisted contour analysis (Cardio 500, Kontron, Munich, Germany) and meas-

\section{STATISTICS}

The data were analysed with the Statistical Package for Social Sciences (SPSS for Windows; SPSS, Munich, Germany). For comparison of two groups the Mann-Whitney $U$ test was used, and for analysis of non-continuous data the two tailed Fisher exact test was employed. Correlation coefficients were generated with the Spearman test. A significant difference between groups was assumed at a level of error of $<5 \%$, test results between $5 \%$ and $10 \%$ were considered as statistical trends. All variables with a potential influence on restenoshowed a statistical trend between patients with end stage renal disease and controls were entered into discriminant analysis to assess their influence on angiographic restenosis.

\section{Results}

PATIENTS

The numbers of symptomatic patients were comparable in the two groups before the intervention. More patients in the control group than in the maintenance dialysis group had had a myocardial infarct before angioplasty (table 1). The cardiovascular risk profile in patients with end stage renal disease differed from controls, as there were significantly more risk factors per patient in the former, as well as a higher prevalence of diabetes mellitus and arterial hypertension. The underlying disease processes which led to end stage renal disease sis which were either significantly different or 
Table 2 Results of coronary angiography, quantitative coronary evaluation, and clinical and angiographic restenosis

\begin{tabular}{|c|c|c|c|}
\hline & $\begin{array}{l}\text { ESRD } \\
(n=20)\end{array}$ & $\begin{array}{l}\text { Controls } \\
(n=20)\end{array}$ & $p$ value \\
\hline \multicolumn{4}{|l|}{ Coronary angiography } \\
\hline Single vessel disease $(\mathrm{n})$ & 5 & 6 & NS \\
\hline Double vessel disease $(\mathrm{n})$ & 8 & 12 & NS \\
\hline Triple vessel disease (n) & 7 & 2 & NS \\
\hline \multicolumn{4}{|l|}{ Vessel of intervention } \\
\hline Left anterior descending coronary artery (n) & 11 & 9 & NS \\
\hline Left circumflex coronary artery (n) & 3 & 5 & NS \\
\hline Right coronary artery $(\mathrm{n})$ & 6 & 6 & NS \\
\hline \multicolumn{4}{|l|}{ Location of intervention } \\
\hline Major branch: proximal part & 10 & 8 & NS \\
\hline Major branch: mid part & \multirow{2}{*}{$\begin{array}{l}9 \\
1\end{array}$} & 10 & NS \\
\hline Major branch: distal part & & \multirow{2}{*}{$\begin{array}{l}2 \\
0\end{array}$} & NS \\
\hline Side branch & 0 & & NS \\
\hline \multicolumn{4}{|l|}{ Morphology of the target lesion } \\
\hline Concentric stenosis (n) & 10 & 11 & NS \\
\hline Eccentric stenosis (n) & 3 & 4 & NS \\
\hline Multiple irregular stenosis (n) & 7 & 5 & NS \\
\hline Angulated vessel (<45\%) (n) & 2 & 1 & NS \\
\hline Calcified stenoses $(\mathrm{n})$ & 7 & 4 & NS \\
\hline Procedural variables of coronary angioplasty & & & \\
\hline Diameter of balloon (mm) (mean (SD)) & $2.7 \quad(0.3)$ & $2.7(0.3)$ & NS \\
\hline Total time of inflation (s) (mean (SD)) & $178 \quad(75)$ & (85) & NS \\
\hline Maximal pressure (bar) (mean (SD)) & $7.7 \quad(2.3)$ & $7.9 \quad(2.0)$ & NS \\
\hline Quantitative coronary angiography before PTCA & & & \\
\hline Minimum luminal diameter $(\mathrm{mm})$ (mean (SD)) & $0.77(0.46)$ & $0.97(0.27)$ & $<0.05$ \\
\hline Reference diameter (mm) (mean (SD)) & $2.59(0.87)$ & $2.90(0.55)$ & $<0.10$ \\
\hline Stenosis $(\%)($ mean $(\mathrm{SD}))$ & $69.7(12.0)$ & $65.8(6.3)$ & NS \\
\hline Immediately after $P T C A$ & & & \\
\hline Minimum luminal diameter $(\mathrm{mm})$ (mean $(\mathrm{SD}))$ & $1.64(0.64)$ & $1.82(0.53)$ & NS \\
\hline Reference diameter (mm) (mean (SD)) & $2.57(0.82)$ & $2.80(0.57)$ & NS \\
\hline Stenosis $(\%)($ mean $(\mathrm{SD}))$ & $37.1 \quad(8.7)$ & $35.3(11.3)$ & NS \\
\hline At follow up & & & \\
\hline Time to control (months) & $6.7 \quad(2.8)$ & $6.4 \quad(2.4)$ & NS \\
\hline Minimal luminal diameter (mm) & $1.23(0.70)$ & $1.53(0.66)$ & NS \\
\hline Reference diameter (mm) & $2.69(0.87)$ & $2.93(0.63)$ & NS \\
\hline Stenosis $(\%)$ & $58.2 \quad(20.5)$ & $47.1 \quad(17.3)$ & $<0.10$ \\
\hline Change in minimum luminal diameter & & & \\
\hline Acute luminal gain (mm) (mean (SD)) & $0.89(0.48)$ & $0.86(0.46)$ & NS \\
\hline Late loss $(\mathrm{mm})($ mean $(\mathrm{SD}))$ & $0.43(0.56)$ & $0.26(0.56)$ & NS \\
\hline Net gain $(\mathrm{mm})($ mean $(\mathrm{SD}))$ & $0.46(0.50)$ & $0.56(0.52)$ & NS \\
\hline Restenosis & & & \\
\hline Angiographic restenosis (n) & 12 & 7 & NS \\
\hline Clinical restenosis $(\mathrm{n})$ & 13 & 7 & NS \\
\hline
\end{tabular}

ESRD, end stage renal disease. stenosis) and location (proximal, middle, or distal part of a major vessel).

Angiographic restenosis, defined by the presence of a haemodynamically relevant stenosis ( $>50 \%$ luminal diameter) was present in $60 \%$ of patients with renal disease and in $35 \%$ of controls on angiographic follow up but did not differ between groups, probably because of the small sample size (table 2) Per cent diameter stenosis showed a statistical trend towards a higher average degree of stenosis in the group with renal disease at the time of follow up.

Clinical restenosis, as defined by recurrence or aggravation of angina, occurred in $65 \%$ of patients with renal disease and in $35 \%$ of the controls. While the diagnostic sensitivity of clinical symptoms for the occurrence of angiographic restenosis was comparable in the two groups ( $75 \%$ in patients with renal disease and $71 \%$ in controls), diagnostic specificity was higher in patients on maintenance dialysis ( $85 \%$ versus $63 \%$; table 2 ).

Analysis of quantitative angiographic variables for both groups combined showed that the severity of the coronary stenosis (per cent diameter stenosis) before the intervention was positively correlated with acute luminal gain $(r=0.57, \mathrm{p}<0.001)$ and acute luminal gain was positively correlated with late luminal loss $(r=0.39, \mathrm{p}=0.05)$ indicating that the severity of vessel injury is a promoter of restenosis. Procedural variables such as the size of the balloon, maximum inflation pressure, and total time of inflation were not related to restenosis.

There were no significant correlations between late luminal loss and fibrinogen or lipid values. Discriminant analysis showed that minimum luminal diameter before angioplasty $(r=-0.79)$ had the highest influence on the occurrence of angiographic restenosis when analysed for both groups combined, followed by fibrinogen $(r=+0.34)$, luminal vessel size as defined by the diameter of the reference segment before angioplasty $(r=+0.32)$, and total cholesterol $(r=+0.20)$.

\section{Discussion}

LABORATORY VARIABLES

Quantitative assessment of cardiovascular risk factors reflected changes in the cardiovascular risk profile, as patients with renal disease showed increases in total cholesterol as well as reductions in HDL cholesterol (table 1). Increases in triglycerides and fibrinogen were highly significant in patients on maintenance dialysis compared with the controls.

QUANTITATIVE CORONARY ANGIOGRAPHY, ANGIOPLASTY, AND RESTENOSIS

The predominant target vessel for intervention was the left anterior descending coronary artery, and there were no significant differences between the two groups in the complexity and angulation of the stenoses that were dilated (table 2). Target vessels in patients with end stage renal disease were smaller, as indicated by the differences in reference diameter and minimum luminal diameter, but stenoses were comparable in their severity (per cent diameter
In this first controlled study which included age and sex matched patients without renal disease, the rate of angiographic restenosis in patients with renal disease was $60 \%$, compared with $35 \%$ in controls. Results from this study indicate that prothrombotic factors and procedural variables - vessel size in particular-may be of relevance for angiographic restenosis in patients with end stage renal disease.

LABORATORY VARIABLES

Fibrinogen concentrations were significantly raised in patients with end stage renal disease compared with the controls, and statistical analysis showed that this haemostatic factor affected the rate of angiographic restenosis. Fibrinogen is the substrate of thrombin and is a major determinant of platelet aggregation and rheological blood properties. ${ }^{14} 15$ Linear interrelations between fibrinogen, thrombin generation, and enhanced endogenous fibrinolytic activity have also been demonstrated. ${ }^{16}{ }^{17}$ 
Table 3 Observational studies on percutaneous transluminal coronary angioplasty in patients with end stage renal disease

\begin{tabular}{llll}
\hline & Kahn $1990^{10}$ & Ahmed $1994^{9}$ & ${\text { Rinehart } 1995^{11}}^{11}$ \\
\hline Patients (n) & 17 & 21 & 24 \\
Short term clinical success (n) & $15 / 17$ & $15 / 21$ & $\star 23 / 25$ \\
Clinical restenosis (n) & $12 / 15$ & $9 / 11$ & $13 / 22$ \\
Angiographic follow up (months) & $1-12$ & $1-12$ & $<12$ \\
Repeat angiography (n) & $11 / 12$ & $7 / 9$ & $13 / 22$ \\
Angiographic restenosis (n) & $\star 26 / 32$ & $7 / 7$ & $9 / 13$ \\
\hline
\end{tabular}

^No of lesions dilated. cal symptoms were re-evaluated angiographically. Given the high specificity of clinical symptoms for the occurrence of angiographic restenosis in patients with end stage renal disease, as documented by our study, the restenosis rate would have been lower in the other studies if all the patients had been followed up angiographically. Furthermore in earlier investigations restenosis was assessed visually while this is the first study employing computer assisted quantitative coronary angiography at baseline and on follow up. It is known that visual evaluation of coronary stenoses is particularly unreliable in the medium range (between $50 \%$ and $90 \%$ diameter stenosis), ${ }^{27}$ which is also the predominant range in which restenoses occur. It is therefore quite likely that the restenosis rate was overestimated in previous investigations.

In the patients with end stage renal disease in our study the changes in quantitative angiographic variables reflected the smaller luminal vessel size and the smaller minimum luminal diameter before angioplasty compared with the controls, which have both been described as predictors of restenosis. ${ }^{28} 29$ Diffuse thickening of the coronary intima and media has been shown to be a dominant feature in experimental models of uraemia. ${ }^{30}$ This has recently been confirmed in human coronary arteries and in internal mammary arteries from patients with end stage renal disease, harvested either postmortem or intraoperatively ( $\mathrm{K}$ Amann, personal communications). This may account for smaller luminal diameters despite comparable locations of the stenosis in the coronary arterial system in patients with end stage renal disease, as the luminal view on coronary angiography gives an incomplete reflection of coronary atherosclerosis. ${ }^{31}$

The acute gain in lumen size did not differ between the two groups. This suggests a more severe degree of vessel injury in relation to vessel size in the patients with end stage renal disease. This is supported by the finding of a greater degree of late luminal loss in patients with renal disease, though that did not reach statistical significance. In conjunction with increased wall stiffness from diffuse narrowing of the vascular wall, this may have led to an increased amount of secondary thrombosis and to the induction of more pronounced proliferative processes. ${ }^{32-34}$ $69 \%$ of cases. The latter results are more comparable with our current findings, where angina had a sensitivity of $75 \%$ in detecting angiographic restenosis. It should be borne in mind, though, that angina was present in $85 \%$ of patients with end stage renal disease before the intervention. Therefore these results only reflect the potential for clinical symptoms to detect restenosis in symptomatic patients; they are not relevant to the primary detection of coronary artery disease where increased numbers of asymptomatic patients are to be expected because of the high prevalence of neuropathy. ${ }^{26}$

The rate of angiographic restenosis is lower than that reported in previous studies $(69 \%$ to $100 \%) .^{8-10}$ This is probably a result of selection bias, as in these studies only patients with clini-

\section{LIMITATIONS OF THE STUDY}

The number of patients included in this retrospective study was small and the quality of the data therefore does not allow us to draw the conclusions that might be derived from a large scale prospective trial. As PTCA is not often performed in patients with end stage renal disease, as indicated by the small case numbers reported from other large centres, the number of patients in this investigation probably reflects the best that can be achieved by a single centre. Therefore prospective trials with a multicentre design are warranted to draw more valid conclusions.

In this study, results based on angiographic vascular morphology have to be viewed with 
particular care. The size of the target vessel and the minimum luminal diameter were smaller in patients with end stage renal disease than in the controls. Since these two features are well accepted predictors of restenosis in the general population, this could represent an error in the selection of the control group. On the other hand a more pronounced narrowing of the vascular lumen may suggest specific features in the pathology of atherosclerosis in patients with end stage renal disease. Given that the control group was also representative in terms of cardiovascular risk profile, our results probably reflect the true situation presenting to the clinician. Definitive answers will only be provided by future investigations with more specific imaging techniques like coronary intravascular ultrasound or angioscopy. Such techniques may clarify the role of vascular calcium content, the lumen to wall ratio, and primary thrombosis at the site of intervention as potential vascular risk factors for coronary restenosis in patients with end stage renal disease.

\section{CLINICAL IMPLICATIONS}

Results from this study imply that procedural and prothrombogenic factors, which are regarded as having an impact on restenosis in the general population, may also contribute to the pathogenesis of restenosis following PTCA in patients with end stage renal disease. Revasularisation procedures which enlarge the vascular lumen more completely, for example stent implantation, ${ }^{35}$ may therefore be of particular therapeutic benefit. Although the prolonged administration of antithrombotic treatment such as aspirin, coumarins, and heparin has not proved to be successful in preventing restenosis in the general population, patients with end stage renal disease are a promising target group for novel antithrombotic interventions because of their high prothrombotic risk. It is therefore premature to rule out PTCA as a revascularisation procedure in patients with end stage renal disease, and prospective interventional trials are warranted which address the specific risk factors in this cardiovascular high risk group.

We thank Nicole Stoltefuss and Sabine Meyer for careful help in the preparation of the manuscript.

1 Lindner A, Charra B, Sherrad DJ, Scribner BH. Accelerated atherosclerosis in prolonged maintenance hemodialysis. $N$ Engl f Med 1974;290:697-701.

2 Hellerstedt WL, Johnson WJ, Ascher N, Kjellstrand CM, Knutson R, Shapiro FL, et al. Survival rates of 2728 patients with end stage renal disease. Mayo Clin Proc 1984; pa:776-83.

3 Gokal R, King J, Bogle S, Marsh F, Oliver D, Jakubowski C, et al. Outcome in patients on continous ambulatory peritoneal dialysis and haemodialysis: 4-year analysis of a prospective multicenter study. Lancet 1987;ii: 1105-9.

4 Raine AEG, Margreiter R, Brunner FP, Ehrich JHH, Geerlings W, Landais P, et al. Report on the management of renal failure in Europe. Nephrol Dial Transplant 1992; 7(supp1 2):7-35

5 Holmes DJ, Vliestra RE, Smith HC, Vetrovec GW, Kent $\mathrm{KM}$, Cowley MJ, et al. Restenosis after percutaneous transluminal coronary angioplasty (PTCA): a report from the PTCA registry of the National Heart, Lung and Blood Institute. Am ₹ Cardiol 1984;53:77-81

6 Nobuyoshi M, Kimura T, Nosaka H, Mioka S, Ueno K, Yokoi $\mathrm{H}$, et al. Restenosis after successful percutaneous transluminal coronary angioplasty: serial angiographic follow-up of 229 patients. $\mathcal{F}$ Am Coll Cardiol 1988;12:616follow.

Serruys PW, Luijten HE, Beatt KJ, Geuskens R, de Feyter $\mathrm{PJ}$, van den Brand $\mathrm{M}$, et al. Incidence of restenosis after successful coronary angioplasty: a time related phenom- enon. A quantitative angiographic study in 342 consecutive patients at 1,2, 3 and 4 months. Circulation 1988;77:361 71 .

8 Ahmed WH, Shubrooks SJ, Gibson CM, Baim DS, Bittl JA. Complications and long term outcome after percutaneous coronary angioplasty in chronic hemodialysis patients. $\mathrm{Am}$ Heart f 1994;128:252-5.

9 Kahn JK, Rutherford BD, McConahay DR, Johnson WL, Giorgi LV, Hartzler GO. Short- and long term outcome of percutaneous transluminal coronary angioplasty in chronic dialysis patients. Am Heart f 1990;1 19:484-9.

10 Rinehart AL, Herzog CA, Collins AJ, Flack JM, Ma JZ, Opsahl JA. A comparison of coronary angioplasty and coronary artery bypass grafting outcomes in chronic dialysis patients. Am f Kidney Dis 1995;25:281-90.

11 Clauss A. Gerinnungsphysiologische Schnellmethode zur Bestimmung des Fibrinogens. Acta Haematol 1957;17:23741 .

12 Ambrose JA, Winters SL, Arora RR, Eng A, Riccio A, Gorin $\mathrm{R}$, et al. Angiographic evaluation of coronary morphoogy in unstable angina. $7 \mathrm{Am}$ Coll Cardiol 1986;7:472-8.

13 Herrington DM, Siebes M, Sokol DK, Siu CO, Walford GD. Variablity in measurements of coronary lumen dimensions using quantitative coronary angiography. $\mathcal{F} \mathrm{Am}$ Coll Cardiol 1993;22:1068-74.

14 Leschke M, Blanke H, Stellwaag M, Motz W, Strauer BE. Hyperfibrinogenämie und pathologische Plasmaviskosität. Dtsch Med Wochenschr 1988;113:1175-81.

15 Leschke M, Schoebel FC, Mecklenbeck W, Stein D, Jax TW, Müller-Gärtner HW, et al. Long-term intermittent urokinase therapy in end stage coronary artery disease and refractory angina pectoris: a randomized dose-response trial. $7 \mathrm{Am}$ Coll Cardiol 1996;27:575-84.

16 Ceriello A, Prisi M, Giacomello R, Stel G, Falleti, Motz E, et al. Fibrinogen plasma levels as a marker of thrombin activation: new insights on the role of fibrinogen as a cardiovascular risk factor. Thromb Haemost 1994;71:593-5.

17 Stein D, Schoebel FC, Heins M, Withold W, Pels K, Jax T, et al. Activation of the fibrinolytic system in patients with hyperfibrinogenemia and coronary artery disease and hyperfibrinogenemia. Thromb Haemost 1997;77:970-4.

8 Gris J, Branger B, Vecina F, Al Sabadani BA, Fourcade J, Schved JF. Increased cardiovascular risk factors and features of endothelial dysfunction in dialyzed uremic patients. Kidney Int 1994;46:807-13.

19 Bauer KA, Rosenberg RD. The pathophysiology of the prothrombotic state in humans: Insights gained from studies using markers of hemostatic system activation. Blood 1987; 70:343-50.

20 Merlini PA, Bauer KA, Oltrona L, Ardissini D, Cattaneo M, Belli C, et al. Persistent activation of coagulation mechanisms in unstable angina and myocardial infarction. Circulation 1994;90:61-8.

21 Leimgruber PP, Roubin GS, Hollmann J, Catsonis GA, Meier B, Douglas IJ, et al. Restenosis after successful coronary angioplasty in patients with single-vessel disease. Circulation 1986;73:710-17.

22 Quigley PJ, Hlatky MA, Hinohara S, Rendell DS, Perz JA, Philipps HR, et al. Repeat percutaneous transluminal coronary angioplasty and predictors of recurrent restenosis. Am f Cardiol 1989;63:409-13.

23 Fuster V, Falk E, Fallon JT, Badimon L, Chesebro JH, Badimon Jj. The three processes leading to post PTCA restenosis: dependence on the lesion substrate. Thromb Haemost 1995;74:552-9.

24 Schoebel FC, Gradaus F, Jax TW, Stein D, Heins M, Borries $\mathrm{M}$, et al. Hämostaseologische RisikofaktorenBorries $\mathrm{M}$, et al. Hamostaseologische Risikofaktoren[abstract]. Z Kardiol 1996;85(supp1 2):284.

25 Shah PK, Amin J. Low high density lipoprotein level is associated with increased restenosis rate after coronary angioplasty. Circulation 1992;85:1279-85.

26 Koch M, Gradaus F, Schoebel FC, Leschke M, Grabensee B. Relevance of cardiovascular risk factors for the prediction of coronary artery disease in diabetic patients on renal replacement therapy. Nephrol Dial Transpl 1997;12: $1187-91$

27 Brown BG, Hillger LA, Lewis C, Zhao XQ, Sacco D, Bisson $\mathrm{B}$, et al. A maximum conficence approach for measuring progression and regression of coronary artery disease in clinical trials. Circulation 1993;87(supp1 II):II66-73.

28 Schwarz F, Preusler W, Reifrat N, Storger H, Baier T, Schlotzer $\mathrm{P}$, et al. Langzeiterfolge nach Koronarangioplastie in Abhängigkeit von der Gefäßgröße. Dtsch Med oplastie in Abhängigkeit von der

29 Hirshfeld JW, Schwartz S, Jugo R, MacDonald RG, Goldberg S, Savage MP, et al. Restenosis after coronary angioplasty: a multivariate statistical model to relate lesion and procedure variables to restenosis. I Am Coll Cardiol 1991;18:647-56.

30 Amann K, Neususs R, Ritz E, Irzyniec T, Wiest G, Mall G. Changes of vascular architecture independent of blood pressure in experimental uremia. Am f Hypertens 1995;8: $409-17$.

31 Topol EJ, Nissen SE. Our preoccupation with coronary luminology - the dissociation between clinical and angiographic findings in ischemic heart disease. Circulation 1995;92:2333-42.

32 Farb A, Virmani R, Atkinson JB, Anderson PG. Long-term histologic patency after percutaneous transluminal histologic patency after percutaneous transluminal greater lumen area. $7 \mathrm{Am}$ Coll Cardiol 1994;24:1229-35.

33 Libby P, Schwartz D, Brogi E, Tanaka H, Clinton SK. A cascade model for restenosis-a special case of atheroscle- 
rosis disease progression. Circulation 1992;86(suppl III): III $47-52$

34 Ip JH, Fuster V, Badimon L, Badimon J Taubman MB, Chesebro JH. Syndromes of accelerated atherosclerosis: role of vascular injury and smooth muscle cell proliferation. 7 Am Coll Cardiol 1990;15:1667-87.

35 Fischman DL, Leon MB, Baim DS, Schatz RA, Savage MP Penn I, et al, for The Stent Restenosis Study Investigators.
A randomized comparison of coronary stent placement and balloon angioplasty in the treatment of coronary artery 6-501.

36 Serruys PW, de Jaegere P, Kiemeneij F, Macaya C, Rutsch W, Heyndrickx G, et al, for the Benestent Study Group. A comparison of balloon-expandable-stent implantation with balloon angioplasty in the treatment of coronary artery disease. $N$ Engl f Med 1994;331:489-95.

\section{IMAGES IN CARDIOLOGY}

\section{An unusual palliative shunt for cyanotic congenital heart disease}

An 11 year old boy was referred for surgical correction of tetralogy of Fallot, having undergone a palliative aortopulmonary shunt in eastern Europe seven years previously. Clinical examination revealed severe central cyanosis and a continuous shunt murmur, as well as a short ejection murmur from the right ventricular outflow tract. Selective angiography of the right subclavian artery demonstrated a direct anastomosis to the right upper pulmonary vein. From the clinical history he had been surprisingly well palliated for several years. The severe stenosis at the anastomotic site had protected the right lung from high pressure and pulmonary oedema, allowing successful repair.

Selective angiogram of the right subclavian artery (SA) in the frontal projection, demonstrated filling of the right upper pulmonary vein (PV) and subsequently the left atrium

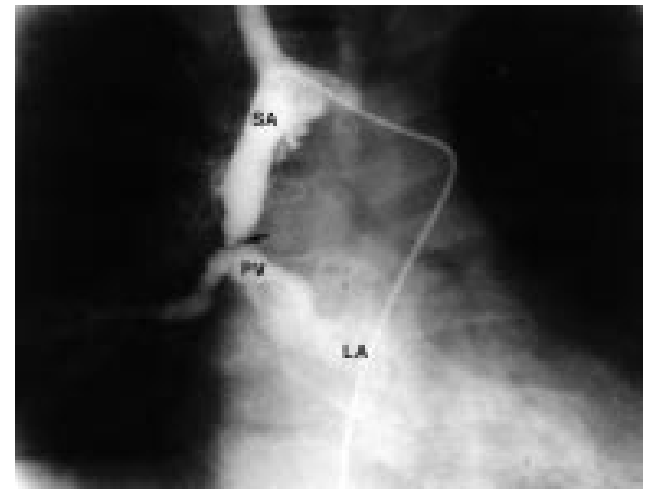

(LA). The arrow denotes the area of severe stenosis at the anastomotic site.

N SREERAM H HENNEVELD J F HITCHCOCK 